\title{
Lúpus eritematoso sistêmico com acometimento neurológico grave: Relato de Caso
}

\author{
Eduardo Lopes ${ }^{1}$; Antônio Carlo Klug Cogo; Carolina Dolinski; \\ Patrícia Formigheri Feldens²; Fabio Cardoso³, Lucas Pereira \\ Mallmann ${ }^{4}$
}

\section{Resumo}

O Lúpus Eritematoso Sistêmico (LES) é uma doença multissistêmica de origem autoimune. A apresentação clínica é variável e a evolução costuma ser crônica, com períodos de exacerbação e remissão. As lesões mais características decorrem de imunocomplexos depositados nos vasos, rins, tecido conjuntivo e pele, mas também podem ocorrer manifestações neurológicas, as quais são mais raras e de difícil diagnóstico. Quando há acometimento do sistema nervoso central, podem ocorrer sintomas como disfunção cognitiva, cefaleia, convulsão, neuropatia periférica e alterações visuais. O fatorantinuclear (FAN), por sua vez, é um dos principais exames laboratoriais usados para o diagnóstico de LES, já que ele é detectado em mais de $95 \%$ dos casos. Em raros casos de LES que apresentam FAN negativo com nefrite, a biópsia renal é necessária porque, além de estabelecer a classificação histológica, contribui para o prognóstico e tratamento, já que exclui outras hipóteses diagnósticas. $O$ presente trabalho tem como objetivo relatar o caso de uma paciente feminina de 23 anos, previamente hígida, internada em uma Unidade de Terapia Intensiva (UTI) com manifestações neurológicas graves (catastrófica) associadas a comprometimento renal com resultado de FAN negativo e diagnóstico de LES estabelecido após a realização de biópsia renal, através do anatomopatológico e principalmente através da imunofluorescência.

Palavras Chave: Lúpus Eritematoso Sistêmico; Nefrite Lúpica, Anticorpos Antinucleares.

\footnotetext{
${ }^{1}$ Graduando do curso de Medicina do Centro Universitário Univates, Lajeado (RS).

2 Médica nefrologista do Hospital Bruno Born, Lajeado (RS), do Hospital Estrela, Estrela (RS) e professora adjunta do curso de Medicina do Centro Universitário Univates, Lajeado (RS).

${ }^{3}$ Médico intensivista e coordenador da UTI adulto do Hospital Bruno Born, Lajeado (RS).

${ }^{4}$ Médico internista no Hospital Bruno Born, Lajeado (RS).
} 


\section{Introdução}

O Lúpus Eritematoso Sistêmico (LES) é uma doença multissistêmica de origem autoimune caracterizada por um vasto conjunto de autoanticorpos antinucleares ou fatores antinucleares (FANs). A apresentação clínica do LES é tão variável que o American College of Rheumatology estabeleceu um conjunto complexo de critérios para este transtorno (KUMAR, 2010). A evolução costuma ser crônica, com períodos de exacerbação e remissão (MINISTÉRIO DA SAÚDE, 2013).

Segundo Borba (2008), o desenvolvimento da doença (de etiologia não totalmente esclarecida) está ligado à predisposição genética e fatores ambientais. As lesões mais caraterísticas decorrem de imunocomplexos depositados nos vasos, rins, tecido conjuntivo e pele (KUMAR, 2010). Dentre essas lesões, a glomerulonefrite é conhecida como uma das complicações mais comuns do LES e está frequentemente associada à presença do FAN e do anti-DNA positivos (CREMA; SKARE, 2013).

Relata-se aqui um caso raro de uma paciente diagnosticada com LES apresentando manifestações neurológicas graves causadas por trombos possivelmente associados à glomerulonefrite secundária. $O$ diagnóstico final deu-se por meio de biópsia renal, tendo em vista que o teste para FAN apresentou resultado negativo.

\section{Objetivo}

Relatar e discutir um caso de lúpus eritematoso sistêmico com manifestações pouco descritas na literatura.

\section{Relato de caso}

Paciente feminina, de 23 anos, previamente hígida, procurou o pronto atendimento com queixa de dois episódios de sincopes no dia da consulta. Referiu que no último mês apresentou perda de peso significativa, cefaleia, artralgia, vertigens, episódios de suores noturnos, além de aumento significativo de linfonodo cervical direito. O exame físico não apresentava alterações significativas.

Retornou ao pronto socorro com quadro de rebaixamento do sensório. (descerebração). Ao exame físico observou-se importante hipotensão, hipertermia e discreta rigidez de nuca. Suspeitou-se inicialmente de encefalite viral ou encefalite relacionada a uma doença reumatológica. Realizou-se punção lombar, que se apresentou normal. 
Prosseguiu-se a investigação, sendo realizados os seguintes exames laboratoriais, os quais revelaram anemia normo/normo ( $\mathrm{Hb} 10,5 \mathrm{~g} / \mathrm{dl}$ e VSG < $100)$, as sorologias para HIV, hepatite $B$ e $C$ e sífilis foram não reagentes, $C 3$ de 43 (reduzido), C4 de 8 (reduzido), FAN (-), Anca (+) , anti-DNA(+), anticardiolipina não reagente e anticoagulante lúpico (-). O exame quantitativo de urina revelou proteinúria em 24 horas de $1940 \mathrm{mg}$. A tomografia de abdômen mostrou lesões vasculares disseminadas no fígado. A tomografia de crânio posterior apresentou alterações difusas da substância branca. O LCR apresentava-se sem alterações. A ressonância magnética de encéfalo apresentou alterações de núcleos da base, da substância branca difusa e do mesencéfalo (compatível com vasculite). A realização da biopsia renal revelou anatomopatológico sem características de vasculite, com glomérulos preservados, presença de corpos hialinos e trombos e a imunofluorescência mostrou a presença de "FullHouse" com complementos.

A investigação para o diagnóstico durou cerca de um mês e o quadro clínico da paciente manteve-se instável durante todo o período, sendo necessária sedação constante. A internação na Unidade de Terapia Intensiva ocorreu desde o início da piora do quadro. Ocorreram múltiplas infecções enquanto aguardava-se o resultado dos exames, além de uma piora constante no quadro neurológico. Iniciou-se pulsoterapia com corticosteroide antes mesmo da definição do diagnóstico, que só foi possível após os achados da biopsia renal. Posteriormente, ainda foram realizadas pulsoterapia com ciclofosfamida e imunoglobulina. Uma melhora razoável no quadro neurológico e uma estabilidade do quadro clínico só foram observadas após o tratamento com este último tratamento.

\section{Discussão}

No LES, o envolvimento do SNC e periférico ocorrem em $24 \%$ a $59 \%$ dos pacientes (SATO, 2008). As manifestações neurológicas, que podem ser encontradas, são de difícil diagnóstico, compreendendo, entre outros sintomas, disfunção cognitiva, cefaleia, convulsão, neuropatia periférica e alterações visuais. Essas manifestações são atribuídas a um processo primário que resulta diretamente de oclusão vascular devido à vasculopatia mediada por imunocomplexos ou por anticorpos antineuronais (FERNANDES, 2000).

Segundo Borba (2008) o FAN é um dos principais exames laboratoriais usados para o diagnóstico de LES. A positividade desse teste serve como triagem em razão de sua sensibilidade (maior que 95\%), sendo altamente improvável a presença da doença se o teste resultar negativo. Em casos de alta probabilidade de LES, mas com FAN negativo, a biópsia renal é necessária 
porque, além de estabelecer a classificação histológica e excluir outras possibilidades diagnósticas, pode ter implicações prognósticas e terapêuticas. (CREMA; SKARE, 2013)

A biópsia renal foi essencial para o diagnóstico do caso apresentado. $O$ histopatológico da nefrite lúpica tem um padrão de imunofluorescência conhecido como "full house", que é descrito como um padrão no qual se detectam simultaneamente depósitos de IgA, IgG, IgM, C1 e C3. A lesão em full house é caraterística da nefrite por LES, mas pode também ser encontrada em casos de endocardite, infecção por HIV, hepatitis C, shunts portosistêmicos e em glomerulonefrite pós-estreptocócica, os quais foram excluídos laboratorialmente e clinicamente.

As manifestações neurológicas catastróficas descritas no caso, que foram o principal acometimento, sugeriam inúmeras hipóteses diagnósticas. Suspeitou-se inicialmente de encefalite viral ou reumatológica. O FAN negativo foi um fator de confusão para o diagnóstico. Dessa forma, é importante que se ressalte, com esse trabalho, que o LES pode apresentar-se com FAN negativo, apesar da raridade desse acontecimento. É fundamental destacar, além do mais, a importância da biópsia renal como auxiliar para o diagnóstico nos casos em que há nefrite, podendo e devendo ser realizada.

\section{Referências}

BORBA, Eduardo Ferreira et al . Consenso de lúpus eritematoso sistêmico.

Rev. Bras. Reumatol., São Paulo, v. 48, n. 4, p. 196-207, Aug. 2008.

Disponível em: <http://www.scielo.br/scielo.php?script=sci_arttext\&pid=S0482$50042008000400002 \&$ Ing=en\&nrm=iso >. Acesso em 15/03/2016.

CREMA, C.; SKARE, T.L. Glomerulonefritelúpica em paciente com fator antinuclear (FAN) negativo. Rev. Med. Res., Curitiba, v.15, n.3, p. 207-210, jul./set. 2013.

FERNANDES J. M. C. et al. Elementos básicos de diagnóstico do lúpus eritematoso sistêmico. Temas de Reumatologia Clínica, v.1, n.3, 2000. Disponível em: $<$ http://www.moreirajr.com.br/revistas.asp?fase=r003\&id_materia $=1563>$. Acesso em: 15/03/2016.

KUMAR et al. Robbins \&Cotran: Bases patológicas das doenças. 8 ed. p. 213-221. São Paulo: Elsevier, 2010.

MINISTÉRIO DA SAÚDE. Protocolo clínico e diretrizes terapeuticas lúpus eritematoso sistêmico. Portanaria no 100 . Fev, 2013. Disponível em: 
<http://bvsms.saude.gov.br/bvs/saudelegis/sas/2013/prt0100_07_02_2013.html >. Acesso em: 15/03/2016.

SATO, E.I. Lupus Eritematoso Sistêmico. In: Júlio C. Voltarelli. (Org.). Imunologia Clínica na prática Médica. São Paulo: Atheneu, 2008, p. 651-662. 